\title{
Morphological Characterization of Prickled and Prickle-free Rubus Using Scanning Electron Microscopy
}

\author{
Archana Khadgi and Courtney A. Weber \\ School of Integrative Plant Science-Horticulture Section, Cornell University, \\ Cornell AgriTech, 630 W. North Street, Geneva, NY 14456
}

Additional index words. blackberry, black raspberry, glandular trichome, prickle, raspberry, simple trichome

\begin{abstract}
Caneberry crops (raspberry and blackberry) are globally commercialized specialty crops with a high fresh market value. Field management of canes and harvesting of fruits can be complicated by the presence of prickles (the botanically accurate term rather than spines or thorns) on the stems, petioles, and underside of the leaves. Both field management and fruit harvesting could be simplified by the development of cultivars with prickle-free canes. Scanning electron microscopy (SEM) was used to analyze and compare prickle development in different $R$ ubus species. Comparisons were made between prickled vs. prickle-free red raspberry (Rubus idaeus L.), black raspberry (Rubus occidentalis L.), blackberry (Rubus hybrid), complex hybrid with purple fruit ( $R$. occidentalis $\times R$. idaeus), and the hairy and prickled wineberry (Rubus phoenicolasius Maxim). Samples from stems and leaves with petioles attached were used for imaging. There were distinct differences between prickled vs. prickle-free phenotypes in each species. The images of prickle development suggest that prickles either develop directly from glandular trichomes (in red raspberry and wineberry) or that the signal originates from glandular trichomes (in blackberry). Black raspberry prickle development was similar to that of blackberry, suggesting that prickles developed after a developmental signal from glandular trichomes rather than as a direct development from glandular trichomes. The prickle development in the purple hybrid was unique in the presence of one-sided lumps in the trichomes, which has not been seen in any other Rubus species to date; however, both prickled and prickle-free plants exhibited simple nonglandular trichomes. Unlike previous studies, an increase in the number of simple trichomes was not specific to prickle-free plants, but rather variability among the different genotypes was observed. This study adds to the basic understanding of prickle development in the genus Rubus as a first step in the development of prickle-free versions of important cultivars through gene-editing procedures for improving the ease of field management and harvesting.
\end{abstract}

Plant trichomes are simple hair-like structures that extend from the epidermal surface of plants and are present on most terrestrial plants (Johnson, 1975). Trichomes increase the ability of the epidermal layer to moderate surface temperatures and reduce transpiration as the pubescence traps air, which effectively thickens the barrier between the epidermis and the environment (Schuepp, 1993). In addition to abiotic stresses, trichomes are known to protect plants against herbivores, insects, pathogens, and mechanical injuries (Barton, 2014; Halpern et al., 2007; Szymanski et al., 2000). Trichomes vary greatly in their morphology, but can be classified into two types: simple trichomes (nonsecreting) and glandular (secreting) trichomes (Wagner

Received for publication 10 Jan. 2020. Accepted for publication 27 Feb. 2020.

Published online 6 April 2020.

C.A.W. is the corresponding author. E-mail: caw34@ cornell.edu.

This is an open access article distributed under the CC BY-NC-ND license (https://creativecommons. org/licenses/by-nc-nd/4.0/). et al., 2004). In Arabidopsis (Arabidopsis thaliana), unicellular simple trichomes have proven to be great models for understanding cell fate and differentiation (Breuer et al., 2009; Marks et al., 2009; Wagner, 1991). Glandular or secreting trichomes are present in many vascular plants and are multicellular structures with secreting glands at the tip of the stalk, which often produce and store terpenoids, phenylpropanoid oils, and other secondary metabolites (Mahmoud and Croteau, 2002; Schilmiller et al., 2008; Wagner et al., 2004). Other epidermal outgrowths include thorns, prickles, and spines. Although these terms refer to botanically different structures with different features, all are commonly referred to as "thorns"; however, botanically, thorns are modified branches and spines are modified leaves, both containing adjoining vascular tissue. In contrast, prickles are formed by multiple cellular divisions of the epidermis and do not contain internal vascular tissue (Bieniek and Millington, 1967; Blaser, 1956; Coyner et al., 2005; Esau, 1977; Posluszny and Fisher, 2000). Most bramble research uses the term thorns to refer to these multicellular epidermal out- growths, but for clarity and as correct botanic terminology, the term prickle for the presence of epidermal appendages and prickle-free for the absence is used in this manuscript.

The genus Rubus is an excellent member of the family Rosaceae to understand prickle initiation and development. Fruits of the genus Rubus, also known as caneberries or brambles, are an important source of cellulose, vitamin E, natural pigments, antioxidants, and phenolic compounds (Beattie et al., 2005). Prickles are an unappealing trait in red and black raspberry and blackberry (Clark et al., 2007), as well as in many wild Rubus species. Prickles complicate both fruit harvesting and field management (pruning, training). Because of this, there have been many efforts to use the prickle-free phenotype in breeding, thus resulting in the pricklefree cultivars such as 'Joan J' and 'Glen Ample' red raspberry ( $R$. idaeus L.) (Finn et al., 2008), and 'Natchez', 'Chester' (Clark and Moore, 2008), 'Apache', and 'Triple Crown' blackberry (R. hybrid), among others. The prickle-free phenotype has long been sought after in blackberry sports of popular cultivars; however, combining the prickle-free trait with other important traits through traditional breeding approaches can be time-consuming and difficult because of polyploidy and/or high heterozygosity among the germplasm. Because the genus has both prickled and prickle-free cultivars with similar genetics, comparisons at both the morphological and molecular levels is possible in understanding prickle development. This knowledge is the first step toward the development of prickle-free versions of economically important cultivars using genome-editing techniques.

An analysis (Coyner et al., 2005) of prickle development using a blackberry prickle chimera provided a significant step in understanding how different embryonic layers $\left(\mathrm{L}_{\mathrm{I}}, \mathrm{L}_{\mathrm{II}}, \mathrm{L}_{\mathrm{III}}\right)$ communicate for prickle formation. In the study, the chimeric blackberry, which produced prickles in only a few regions of the plant, was characterized. The results provided evidence of communication between epidermal and cortical cells for prickle development in blackberry. On the removal of outermost layer $\left(\mathrm{L}_{\mathrm{I}}\right.$-derived epidermal layer) of the prickle-free area, prickles were produced from the layer underneath $\left(\mathrm{L}_{\mathrm{II}}\right.$-derived cambial layer), suggesting the presence of molecular cues between the two layers. There have been additional studies in understanding morphological structures, histochemical features, origin, and genetic patterns of prickles in Rosaceous species (Asano et al., 2008; Kellogg et al., 2011; Rajapakse et al., 2001). Although prickles of red raspberry consist of only epidermal tissues, prickles of blackberry comprise both epidermal and cortical tissues but still lack vasculature (Kellogg, 2009). There is limited knowledge regarding the molecular pathways contributing to the pricklefree trait, which has hindered the application of modern molecular approaches to studying 
prickle development. To identify the molecular pathways controlling prickle development, a thorough understanding of prickle morphology in the genus is required to serve as the foundation for these additional studies.

A previous morphological study on understanding prickle development in Rubus suggested that prickles are modified glandular trichomes (Kellogg et al., 2011). In the study, the prickled red raspberry cultivar Heritage and the low prickle cultivar Canby, the prickle-free blackberry cultivar Arapaho and the fully prickled cultivar Prime Jim, and the prickled 'Radtko' rose cultivar (Rosa hybrida L.) were examined. However, a genetically prickle-free red raspberry cultivar was not included for comparison. Without this comparison, it could not be determined if glandular trichomes were present in the prickle-free genotype/phenotype or if the development was halted prematurely as in the case of 'Canby', which is often described as prickle-free but in reality is functionally prickle-free on most of the mature tissue. 'Canby' produces glandular trichomes that mature into prickles only in some instances.

In this study, morphological differences between prickled and prickle-free genotypes/ phenotypes in different Rubus species were compared to better understand prickle development within the genus. To better understand the process of prickle development in the genus, scanning electron micrographs of different members of the genus were examined, including prickled red raspberry, prickle-free red raspberry, prickled blackberry, prickle-free blackberry, prickled black raspberry $(R$. occidentalis L.), prickle-free black raspberry, and a prickled complex hybrid with purple fruit (purple hybrid) ( $R$. occidentalis $\times R$. idaeus). The prickled wineberry ( $R$. phoenicolasius L.), which also produces long, dense hairs, was included to examine the contrast between prickle and hair development.

\section{Materials and Methods}

Plant materials used. Stem, leaf, and petiole tissue samples from prickled red raspberry 'Caroline', prickle-free red raspberry 'Joan J', thorny blackberry NYB10-02, prickle-free blackberry 'Chester', thorny black raspberry 'Hanover', prickle-free black raspberry NY15-39bT, prickled purple hybrid NY13-30p, and hairy/prickled $R$. phoenicolasius were collected for this study. It should be noted that the prickle-free phenotype has not been identified in black raspberry or wineberry germplasm. The prickle-free black raspberry type examined here was developed by introgressing the trait from red raspberry through multiple generations of backcrossing into a black raspberry genetic background. The prickle-free trait used originated from the same genetic source as prickle-free in 'Joan J'.

All plant specimens were grown in the greenhouse at Cornell AgriTech, Geneva, NY. In addition, a controlled hybridization was made between 'Joan J' and 'Caroline' to obtain a population segregating for prickles. Seeds from this cross were collected, sterilized, and cultured in media for germination in a growth chamber. After germination, the seedlings were transferred to soil and grown in a growth chamber before transfer to a greenhouse. The population segregated almost perfectly $1: 1$ for the absence/presence of prickles. Images from all the individuals, including segregating progeny from the 'Joan $\mathrm{J}$ ' $\times$ 'Caroline' population, were examined using a scanning electron microscope.

Microscopy. SEM was conducted on 24 samples of red raspberry collected from three plants each of 'Caroline' and 'Joan J', and three progeny each of prickled and pricklefree. Two samples were collected from each of these plants, one from the main stem and one from the leaf midvein with attached petioles. An additional 13 samples were taken from the prickled purple hybrid (1), prickled black raspberry (3), prickle-free black raspberry (3), prickled blackberry (2), and prickle-free blackberry (3), as well as a main stem sample of $R$. phoenicolasius (1).

Tissues were collected at various stages of prickle development from fresh green to matured lignified brownish prickles. Samples were prepared using the procedure of Cornell Center for Materials Research, Cornell University, beginning with overnight fixation in ice-cold $2 \%$ glutaraldehyde in $0.05 \mathrm{M}$ cacodylate buffer, $\mathrm{pH}$ 7.4. The tissues were then rinsed with buffer three times for $10 \mathrm{~min}$ each followed by secondary fixation using ice-cold osmium tetroxide $\left(\mathrm{OsO}_{4}\right)$ for $2 \mathrm{~h}$. The samples were subsequently dehydrated through a series of ethanol soaks of $25 \%$ (10 min), $50 \%$ (10 min), 70\% (overnight), 95\% (10 min), and $100 \%$ (overnight). The samples were then critical point dried using dry carbon dioxide with exchange conditions of $10^{\circ} \mathrm{C}$ at $3.4 \mathrm{~atm}(1 \mathrm{~atm}=101.325 \mathrm{kPa})$ and then at $31{ }^{\circ} \mathrm{C}$ at $4.76 \mathrm{~atm}$. The dried samples were sputter coated with gold (Desk IV cold sputter coater; Denton Vacuum, Moorestown, NJ) and viewed using an Aspex PICA 1020 scanning electron microscope (Aspex, Delmont, PA).

Prickle heights, basal widths, and cell mass structure width measurements. Adobe Photoshop C2S (Adobe, San Jose, CA) was used to measure heights and basal widths of prickles, glandular trichomes, and cell mass structures. Comparisons were made for each of the prickle development stages. SEM images in the same focal plane that represented different stages of prickle development were chosen for measurements from more than 400 images. For stage I in red raspberry, the mean dimensions of cell mass structures on the epidermal surfaces were calculated for 15 and 13 structures for 'Caroline' and the prickled progeny, respectively. For stages II and III, the mean heights and widths of the prickles and widths of cell mass structures were calculated from 12 and 14 developing prickles with cell mass structure still attached. For stage IV in red raspberry, the mean height and width of 16 and 14 matured prickles were calculated for 'Caroline' and

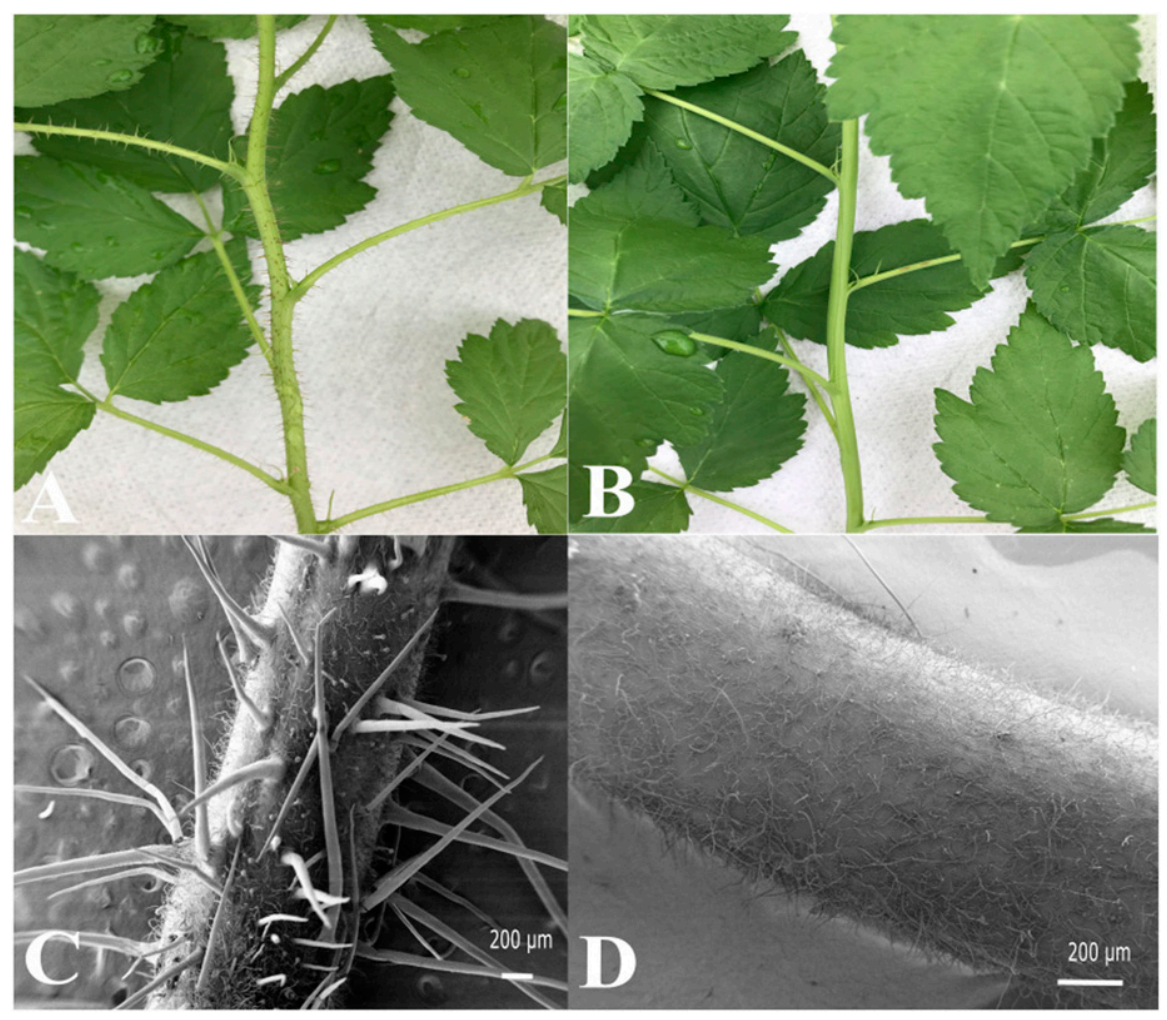

Fig. 1. Gross morphology of Rubus idaeus L. (red raspberry) 'Caroline' and 'Joan J' showing (A) prickled and (B) prickle-free stems and petioles. SEM micrographs showing $(\mathbf{C})$ prickles and simple trichomes on a prickled stem and (D) simple trichomes on the prickle-free stem. 
the prickled progeny, respectively. Similar comparisons of prickle heights, basal widths, and cell mass structure widths were also made in black raspberry, blackberry, purple hybrid, and wineberry. For black raspberry, 10 stage I, 15 stage II and III, and 14 stage IV (mature) prickles were measured. For blackberry, 11 stage II and III and 13 stage IV prickles were measured. In the purple hybrid, 12 stage II and III prickles and 12 stage IV prickles were measured. Because of the spar- sity of prickles in blackberry and purple hybrid and the relatively few samples examined, no stage I prickles were observed. The prickle density in wineberry was higher, enabling the measurement of 21 stage I, 18 stage II and III, and 17 stage IV prickles.

\section{Results}

Comparisons were made within red raspberry samples as well as between different

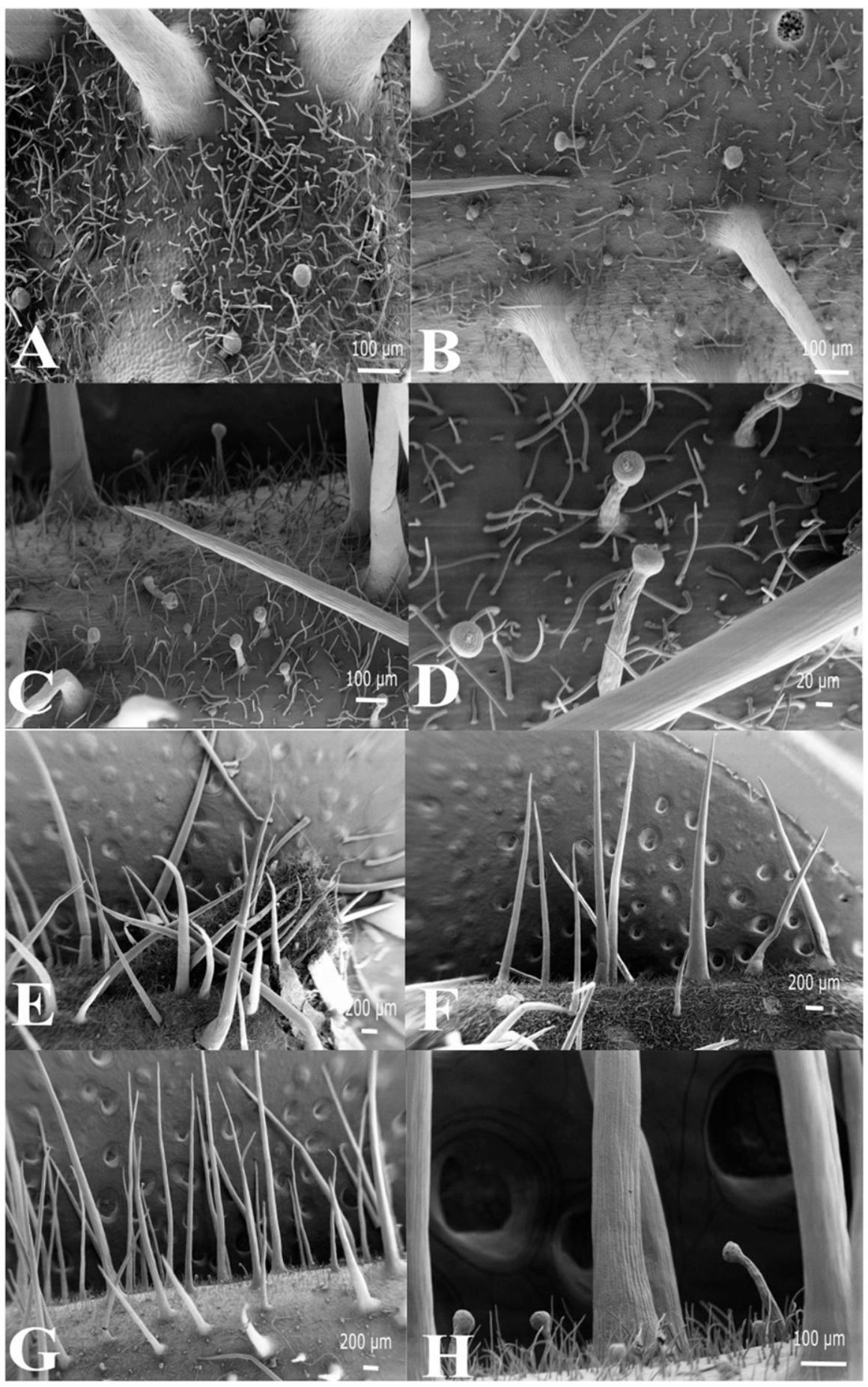

Fig. 2. Scanning electron micrographs of Rubus idaeus L. (red raspberry) 'Caroline'. (A, B) Cell mass structure on the epidermis (stage I). (C, D) Emerging and growing stalk beneath the cell mass structure (stage II). (E, F) Prickle undergoing maturation without the cell mass structure (Stage III). (G, H) Matured, lignified prickles (stage IV) (stage II prickles are also visible in $\mathbf{H}$ ).

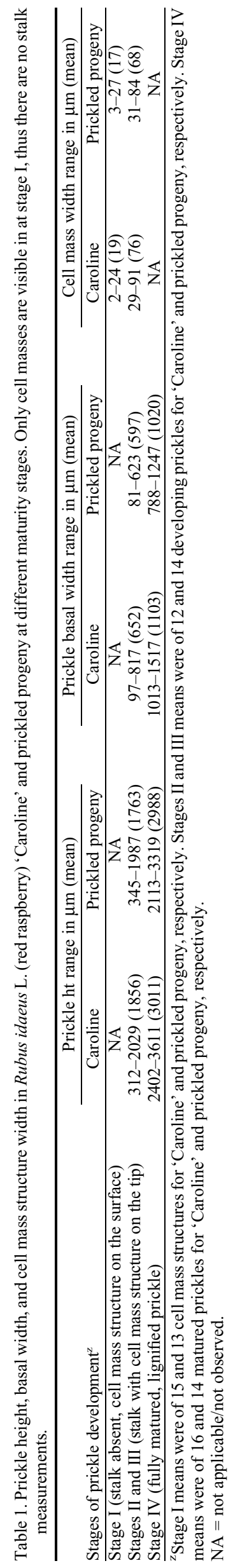

HortScience Vol. 55(5) May 2020 
Rubus species. In red raspberry, the prickle development was compared between 'Caroline' and 'Joan J' and also among the prickled and prickle-free progeny obtained by hybridizing these two parents. Further comparisons were made between different Rubus species, which included red raspberry, blackberry, purple hybrid, black raspberry, and wineberry. The images shown in this article were selected from more than 400 images to best represent different stages of prickle development in all the species but are not necessarily the images used to measure the prickle dimensions.

Morphological comparisons between prickled and prickle-free red raspberry ('Caroline' and 'Joan J' and their hybrid progeny), prickled and prickle-free blackberry (NYB1002 and 'Chester'), prickled and prickle-free black raspberry ('Hanover' and NY1539bT), prickled purple hybrid (NY13-30p), and prickled wineberry showed that prickled and prickle-free types differ phenotypically on the basis of presence or absence of prickles on the outer surface of stem, petioles, and leaves (Fig. 1). SEM revealed the difference between development and final morphology in prickled and prickle-free plants. The surface of prickled individuals was covered with few to many simple, nonglandular trichomes in the different species, few to many prickles, cell mass structures (glandular trichomes), and prickles with a cell mass structure on the tip. Unlike prickled samples, the surfaces of prickle-free samples were covered with only simple, nonglandular trichomes in all the species observed.

Prickle development in 'Caroline' and prickled progeny. SEM revealed that the surface of prickled 'Caroline' and progeny was covered with a dense layer of simple trichomes, matured prickles, developing prickles, and cell mass structures. Similar to Kellogg et al. (2011), all four stages of prickle development were observed. Stage I was characterized by the presence of a cell mass structure on the epidermal surface of the stem, petioles, and underside of the leaves (Fig. 2A and B). The mean width of this cell mass structure was $19 \mu \mathrm{m}$ in 'Caroline' and $17 \mu \mathrm{m}$ in the prickled progeny. At stage II, the stalk emerged from the base of the cell mass structure lifting this structure upward (Fig. 2C and D). At stage III, the cell mass is missing and presumed to have fallen off with the stalk continuing to grow, moving distally from the stem (Fig. 2E and F). The mean prickle height and prickle basal width in 'Caroline' was $1856 \mu \mathrm{m}$ and $652 \mu \mathrm{m}$, respectively. Similarly, the mean prickle height and prickle basal width in the prickled progeny was $1763 \mu \mathrm{m}$ and $597 \mu \mathrm{m}$, respectively. The mean width of the cell mass structure at the tip of the developing stalk in stage II was $76 \mu \mathrm{m}$ and $68 \mu \mathrm{m}$ in 'Caroline' and prickled progeny, respectively. Stage IV in prickle development indicates fully matured prickles, which is determined by the lignification of the prickles (Fig. 2G and H). The mean matured prickle height and prickle basal width in 'Caroline' was $3011 \mu \mathrm{m}$ and
$1103 \mu \mathrm{m}$, respectively. Similarly, the mean matured prickle height and prickle basal width in the prickled progeny was $2988 \mu \mathrm{m}$ and $1020 \mu \mathrm{m}$, respectively. A summary of the mean prickle height, basal width, and cell mass structure width in 'Caroline' and prickled progeny is provided in Table 1 .

Simple trichomes in 'Joan J' and pricklefree progeny. Unlike prickled red raspberry, prickle-free 'Joan J' and progeny completely lacked cell mass structures indicative of the development of prickles. In the prickled types, the presence of cell mass structures and developing prickles were also observed in the underside of the leaves (Fig. 3A and B). In contrast, prickle-free 'Joan J' and progeny completely lacked these cell mass structures and developing prickles on the surface of the stem and underside of the leaves. Only a layer of simple, nonglandular trichomes was observed in these prickle-free types (Fig. 4AD). Unlike Kellogg et al. (2011), an increase in the number of simple trichomes specific to prickle-free types was not observed, but rather variation among the samples.

Prickle development in blackberry. Compared with red raspberry, blackberry prickle density is often sparse on the stems and petioles (Fig. 5A-D), although densely prickled types do exist. Consequently, few cell mass structures were observed in this study on the blackberry samples, and only prickle stages II, III, and IV were observed. Nonlignified prickles, corresponding to stages II and III, were observed in the prickled phenotype with the cell mass structures still

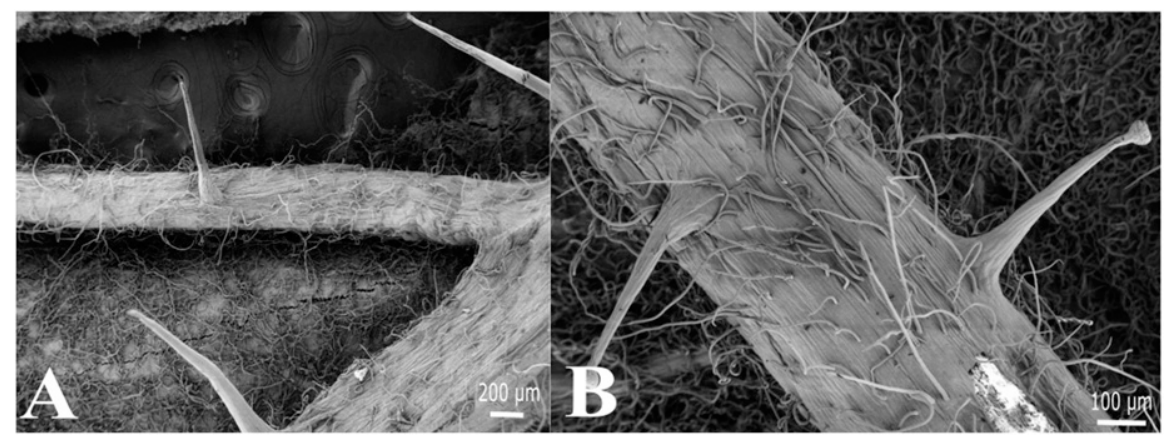

Fig. 3. Scanning electron micrographs of Rubus idaeus L. (red raspberry). (A, B) Developing and mature prickles on the underside leaf veins of 'Caroline' and prickled progeny. Note the dense layer of simple trichomes on the under leaf and vein surface.

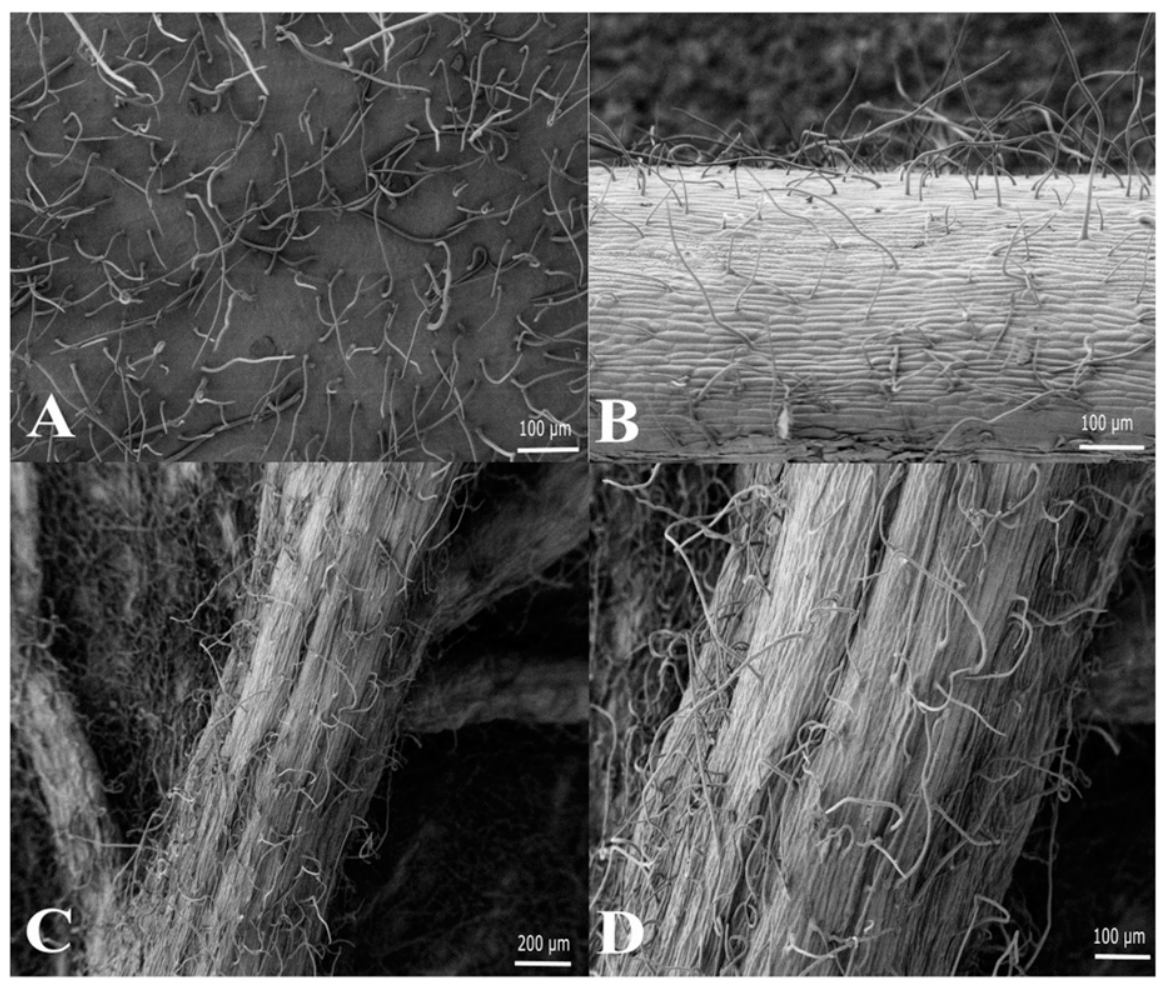

Fig. 4. Scanning electron micrographs of Rubus idaeus L. (red raspberry). (A, B) Simple trichomes on the epidermis of the stem of 'Joan J' and prickle-free progeny. (C, D) Simple trichomes on the underside of the leaves of 'Joan J' and prickle-free progeny. 


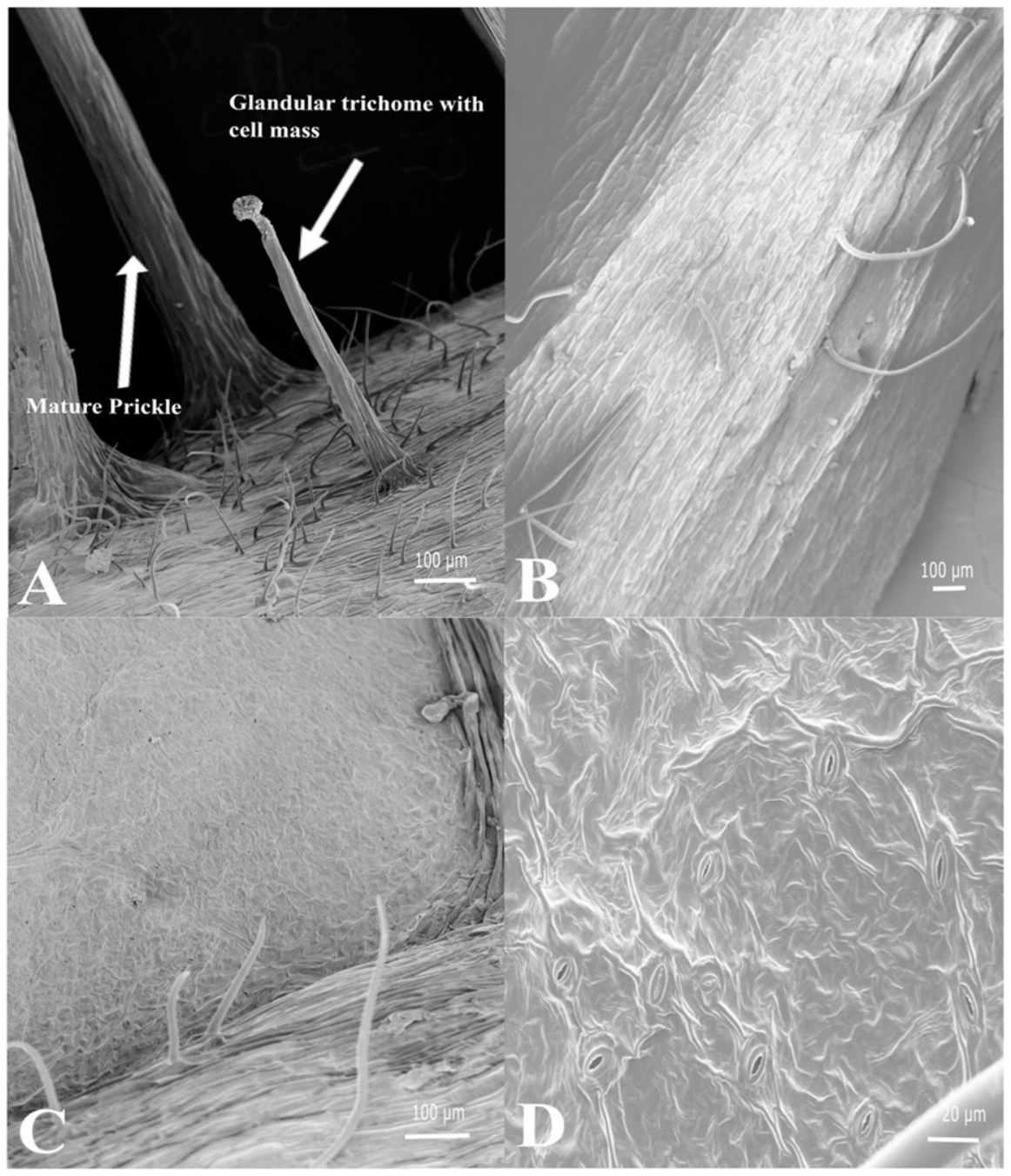

Fig. 5. Scanning electron micrographs of Rubus hybrid (blackberry). (A) Prickles, glandular trichome, and simple trichomes on the stem of prickled blackberry. (B) Simple trichomes on the stem of prickled blackberry. (C) Prickles and visible stomata underside of the leaf of prickled blackberry. (D) Higher magnification of stomata on the underside of the leaf of prickle-free blackberry.

attached at the top, as well as fully matured prickles. Even though not all of the prickle formation stages were observed, a similar lack of the cell mass structures in the pricklefree blackberry phenotype was observed. The mean height and basal width of fully matured prickles in blackberry was $5124 \mu \mathrm{m}$ and $1619 \mu \mathrm{m}$, respectively (Table 2). In addition, simple, nonglandular trichome density in prickle-free blackberry was less than in prickled blackberry.

Prickle development in black raspberry. Unlike red raspberry, black raspberry had few simple, nonglandular trichomes on the stem of the prickled plant (Fig. 6A). Similar to blackberry, prickle density on the stems is relatively low in black raspberry, which made it difficult to obtain clear images of all the stages of prickle development in the samples examined (Fig. 6A and B). The few prickles with the cell mass structures present were not fully matured and were consistent with early prickle development stages (Fig. 6C). Moreover, prickle-free black raspberry completely lacked the cell mass structures, similar to that observed in prickle-free red raspberry and blackberry (Fig. 6D). The mean prickle height and prickle basal width of fully matured prickle in black raspberry was $2563 \mu \mathrm{m}$ and $852 \mu \mathrm{m}$, respectively (Table 2). The underside of the leaf of prickled black raspberry showed the presence of prickles with a similar amount of simple, nonglandular trichomes as seen on red raspberry. Leaves in general had a dense layer of simple trichomes in all species. Prickle-free black raspberry stems showed similar numbers of simple trichomes as compared with prickle-free red raspberry. However, prickled black raspberry stems had fewer simple trichomes compared with prickled red raspberry.

Prickle development in prickled purple hybrid. Unlike red raspberry, blackberry, and black raspberry, cell mass structures were not observed on the stem or underside of the leaf in the purple hybrid. Moreover, this genotype had very few simple trichomes on the stem compared with the other species samples. Interestingly, the purple hybrid leaf samples showed a dense layer of simple trichomes. In

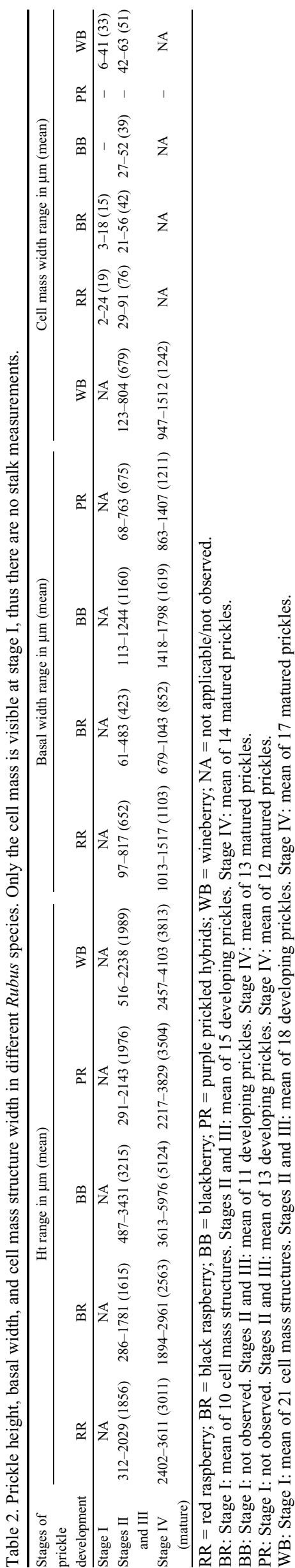

HortScience Vol. 55(5) May 2020 
addition, the images showed the presence of a cell mass on the side of many of what appear to be simple trichomes (Fig. 7A-D), which was not observed in any of the other species samples. Mature prickles were observed in the purple hybrid samples and the mean height and basal width of these was $3504 \mu \mathrm{m}$ and $1211 \mu \mathrm{m}$, respectively (Table 2 ).

Prickle development in wineberry $(R$. phoenicolasius). Prickled wineberry was included in this study because of its unique feature of developing simple nonglandular trichomes, glandular hairs, and prickles (Fig. 8A-C). In addition, the prickles develop a more pronounced curved shape (hook-like) unlike the other Rubus species in this study. Similar to red raspberry, cell mass structures associated with prickle development were observed, but these were also associated with the hair development. All of the different stages of prickle development were observed in wineberry. The mean height and basal width of matured prickles in wineberry were $3813 \mu \mathrm{m}$ and $1242 \mu \mathrm{m}$, respectively (Table 2 ). The mean width of the cell mass structure at the tip of the developing prickle in stage II was $51 \mu \mathrm{m}$.

\section{Discussion}

Simple nonglandular trichomes have been well characterized in Arabidopsis. The transcriptional regulation of the development and patterning of these unicellular trichomes is well studied (Grebe, 2012; Ishida et al., 2008). However, there has been limited study in understanding the development and transcriptional regulation of glandular trichomes. Morphological analysis of the prickled raspberry cultivars Heritage and Canby has shown a correlation between the presence of glandular trichomes and developing prickles (Kellogg et al., 2011). Larger cell mass structures led to prickle development in Heritage and Canby and smaller or no cell mass structure led to almost prickle-free or completely prickle-free raspberry cane sections, respectively. A prickled and prickle-free red raspberry, black raspberry and blackberry, a prickled purple hybrid raspberry, and a prickled wineberry were examined in this study to further understand prickle development in the genus Rubus. The observations reinforce the conclusion from a previous study that prickles in Rubus develop directly from glandular trichomes, or that the signal to initiate development arises from glandular trichomes (Kellogg et al., 2011), as is the case in Solanum viarum dunal (Pandey et al., 2018).

Prickle development can be observed on very young plants in the genus Rubus with prickles visible on the stems 10 to $15 \mathrm{~d}$ after seed germination at approximately the 4- to 5-leaf stage of the seedlings. However, it is noteworthy that simple trichomes are present from the very earliest development stages and can be seen even on the surface of the cotyledons. Despite the presence or absence of glandular trichomes, both the prickled and prickle-free plants exhibit few to many simple trichomes, suggesting simple trichomes

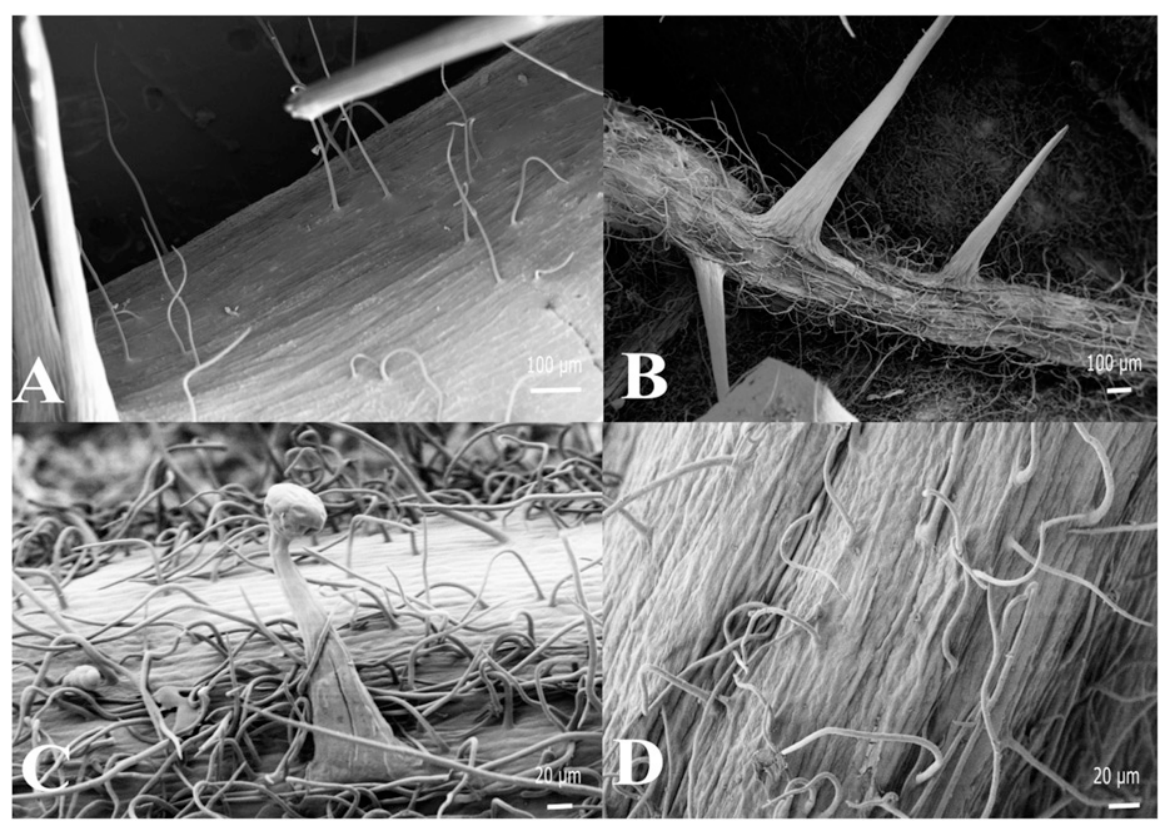

Fig. 6. Scanning electron micrographs of Rubus occidentalis L. (black raspberry). (A) Prickles and simple trichomes on the stem. (B) Prickles and simple trichomes on the underside of the leaf and leaf vein. (C) Immature prickle with cell mass structure on the tip. (D) Simple trichomes on prickle-free plant stem surface.

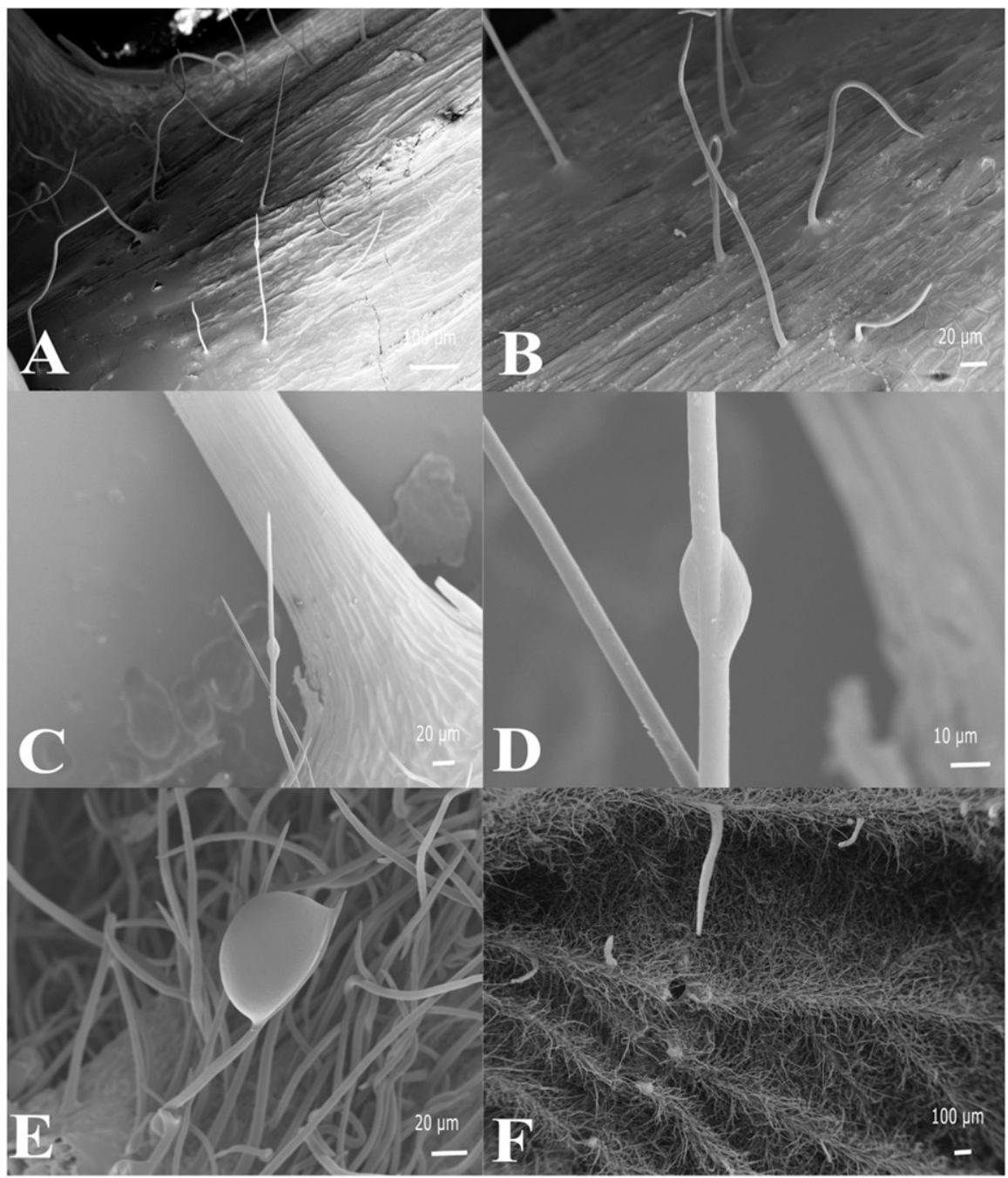

Fig. 7. Scanning electron micrographs of Rubus occidentalis $\times$ Rubus idaeus (purple hybrid). (A-C) Prickles, simple trichomes, and trichomes with lumps on stem surface. (D) Lump on a trichome. (E, F) Prickles and simple trichomes on the underside the leaf. 


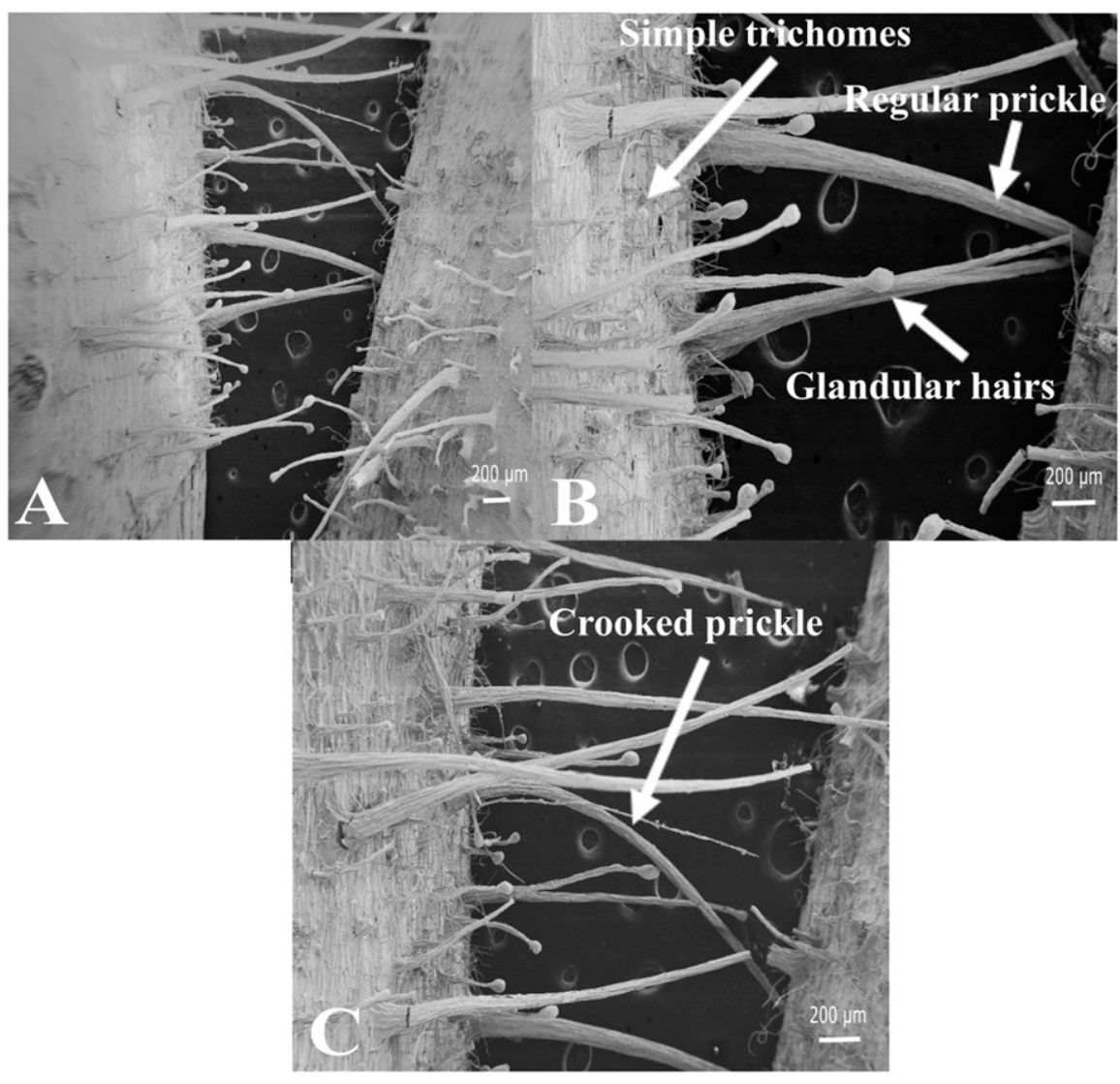

Fig. 8. Scanning electron micrographs of Rubus phoenicolasius Maxim (wineberry). (A-C) Hairs, developing prickles, simple trichomes, and mature curved prickles on the stem.

may not be directly linked to prickle development. However, unlike the observation of increased simple trichome number in pricklefree cultivars (Kellogg et al., 2011), this study found that prickle-free genotypes/phenotypes did not necessarily have an increased number of simple trichomes, as demonstrated in Fig. 9.

Prickle development in red raspberry followed a series of development stages, as suggested earlier by Kellogg et al. (2011). The surface of prickled raspberry was covered with a dense layer of simple trichomes, matured prickles, developing prickles, and cell mass structures thought to be glandular trichomes that would eventually develop into prickles. The development followed four distinct stages in which these glandular trichomes first appear as cell mass structures on the epidermal surface of the stem or leaves. Once the protrusion is observed, a stalk is seen to be growing underneath the cellular mass. These stalks keep growing in both length and width. The glandular cell mass at the tip of the stalk appears to senesce and abscise as the prickle develops and advances to stage IV. No intermediate phase for the cell mass was observed, such as breaking down or thinning into a point in more than 400 images examined. This indicates that the cell mass abscises before lignification and final maturation when the prickles become rigid. In contrast, the surfaces of prickle-free samples were covered only with simple, nonglandular trichomes with no signs of cell mass struc- tures or glandular trichomes present. These structures were also missing from petioles and the underside of the leaves, suggesting that prickle development and simple, nonglandular trichome development are not connected.

The presence of glandular trichomes was also observed in conjunction with prickle development in prickled blackberry. Glandular trichomes in prickle-free blackberry were completely absent, further corroborating the association between glandular trichomes and prickle development. Kellogg et al. (2011) reported the presence of $30 \%$ more simple trichomes on pickle-free 'Arapaho' compared with prickled 'Prime Jim'. However, here the prickle-free blackberry 'Chester' had fewer simple trichomes compared with the prickled blackberry NYB10-02. Both stems and leaves of 'Chester' had very few simple trichomes, so that even the stomata were clearly visible on the leaf underside. This suggests the variability in the simple trichome density is unrelated to the presence of prickles, but rather natural variation among genotypes.

A relationship between the presence of glandular trichomes and prickle development was also observed in black raspberry. Immature prickles were observed (stage II or III) on both the stems and underside of the leaf similar to that observed in red raspberry. Moreover, prickle-free black raspberry completely lacked these cell mass structures, reinforcing the asso- ciation of these structures with prickle development. However, unlike red raspberry, black raspberry had fewer simple trichomes on the stem of the prickled plant.

The association between cell masses and prickle development in purple hybrid was inconclusive because of the failure to find early cell mass structures on the stem of purple hybrid. Examination of additional samples would be required to confirm the relationship in the interspecific hybrids. Unlike red raspberry, black raspberry, and blackberry, no cell mass structures were observed on the stem or underside of the leaf in the purple hybrid. Many trichomes contained lumps on the side of the developing prickle that resembled the glandular cell masses observed at the tip of developing prickles in the other species. These lumps were not observed in any other species examined in this study and require further examination. It is possible that the interspecific nature of the genotype produces conflicting signals during the prickle and trichome development process that originate from the original species genomes. These potentially conflicting signals for cell mass development may result in partial detachment that does not hinder full prickle development. This may lead to a hybrid prickle and trichome development that differs from either of the progenitor species, $R$. idaeus $\mathrm{L}$. and $R$. occidentalis $\mathrm{L}$. Interestingly, the purple hybrid leaf showed a higher density of simple trichomes than either of the progenitor species samples in this study. This could be indicative of the hybrid nature of the genotype or natural variation between genotypes. Observation of additional hybrid genotypes is required to determine the explanation.

Wineberry ( $R$. phoenicolasius) did show the association between the presence of glandular trichomes and prickle development. This species is both very hairy and develops prominent hook-shaped prickles. This mature prickle shape is unlike those of the other Rubus species in this study but not uncommon in the genus Rubus. Similar to red raspberry, many cell mass structures were observed in association with prickle development. Moreover, these cell mass structures were found to be associated with the dense layer of developing hairs observed in the images. All the stages of prickle development were observed in wineberry; however, the density of prickles is much lower than that of the surrounding glandular hairs. It is possible that a subset of hairs continues to develop into prickles through another genetic signal. The combination of glandular hairs and mature prickles is unusual in the genus Rubus. It is possible the hair development is similar in process to prickle development, although the literature suggests a different locus for the genetic control of hair development (Crane and Lawrence, 1931). Comparing prickled wineberry with the prickle-free type would have been more informative but was not possible because the prickle-free phenotype is not known to exist in the species germplasm. This circumstance warrants further 


\section{Presence of simple trichomes on prickled and prickle-free}

stem

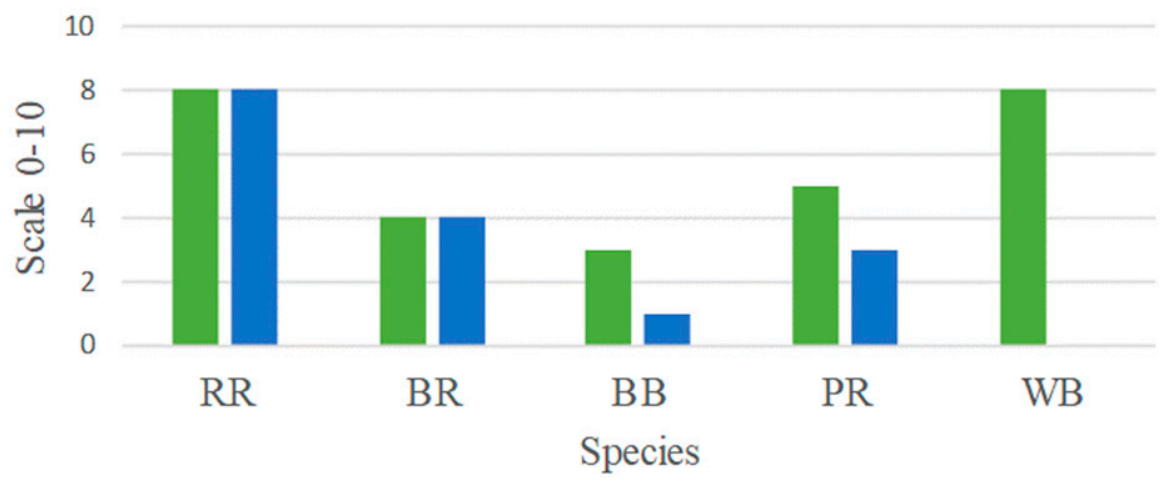

\section{- Prickled Stem a Prickle-free Stem}

\section{Presence of simple trichomes on prickled and prickle-free leaves}

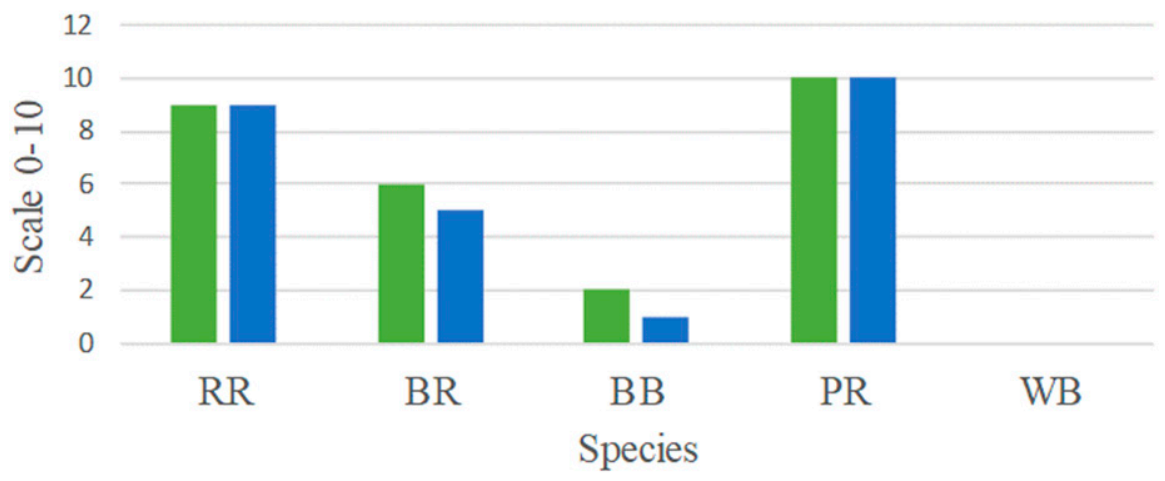

\section{- Prickled Leaf $\quad$ Prickle-free Leaf}

Fig. 9. Comparison of trichome density present in different Rubus species on a scale of 0 to $10(0=$ absent): (A) prickled and prickle-free stems and (B) prickled and prickle-free leaves. $\mathrm{RR}=$ red raspberry; $\mathrm{BR}=$ black raspberry; $\mathrm{BB}=$ blackberry; $\mathrm{PR}=$ purple hybrid; $\mathrm{WB}=$ wineberry.

investigation to elucidate the control of hair development.

Although prickle development in all of the species in this study followed a similar pattern, there were differences in the specific structures. Most of the evidence examined reinforces the association between the presence of glandular trichomes/cell mass structures and prickle development. Further examination of the genetic control of prickle development in Rubus species can elucidate the signaling pathway controlling this trait and lead to gene candidates for identifying the prickle-free allele. Understanding prickle development both at the morphological and molecular levels could lead to the development of prickle-free versions of popular cultivars using geneediting techniques.

\section{Literature Cited}

Asano, G., R. Kubo, and S. Tanimoto. 2008. Growth, structure and lignin localization in rose prickle. Bull. Fac. Agr. Saga Univ. 93:117-125.
Barton, K.E. 2014. Prickles, latex, and tolerance in the endemic hawaiian prickly poppy (Argemone glauca): Variation between populations, across ontogeny, and in response to abiotic factors. Oecologia 174:1273-1281.

Beattie, J., A. Crozier, and G.G. Duthie. 2005. Potential health benefits of berries. Curr. Nutr. Food Sci. 1(1):71-86.

Bieniek, M.E. and W. Millington. 1967. Differentiation of lateral shoots as thorns in Ulex europaeus. Amer. J. Bot. 54(1):61-70.

Blaser, H.W. 1956. Morphology of the determinate thorn-shoots of Gleditsia. Amer. J. Bot. 43(1):22-28.

Breuer, C., A. Kawamura, T. Ichikawa, R. Tominaga-Wada, T. Wada, Y. Kondou, S. Muto, M. Matsui, and K. Sugimoto. 2009. The trihelix transcription factor GTL1 regulates ploidydependent cell growth in the Arabidopsis trichome. Plant Cell 21(8):2307-2322.

Clark, J.R. and J.N. Moore. 2008. 'Natchez' thornless blackberry. HortScience 43:1897-1899.

Clark, J.R., E.T. Stafne, H.K. Hall, and C.E. Finn. 2007. Blackberry breeding and genetics. Plant Breed. Rev. 29:19-144.
Coyner, M., R.M. Skirvin, M. Norton, and A. Otterbacher. 2005. Thornlessness in blackberries: A review. Small Fruits Rev. 4(2):83-106.

Crane, M. and W. Lawrence. 1931. Inheritance of sex, colour and hairiness in the raspberry, Rubus idaeus L. J. Gen 24(2):243-255.

Esau, K. 1977. Anatomy of seed plants. 2nd ed. John Wiley and Sons. Inc., New York, NY.

Finn, C., P. Moore, and C. Kempler. 2008. Raspberry cultivars: What's new? What's succeeding? Where are the breeding programs headed? Acta Hort. 777:33-40.

Grebe, M. 2012. The patterning of epidermal hairs in Arabidopsis - updated. Curr. Opin. Plant Biol. 15(1):31-37.

Halpern, M., D. Raats, and S. Lev-Yadun. 2007. The potential anti-herbivory role of microorganisms on plant thorns. Plant Sign. Behav. 2(6):503-504.

Ishida, T., T. Kurata, K. Okada, and T. Wada. 2008. A genetic regulatory network in the development of trichomes and root hairs. Annu. Rev. Plant Biol. 59:365-386.

Johnson, H.B. 1975. Plant pubescence: An ecological perspective. Bot. Rev. 41:233-258.

Kellogg, A.A. 2009. Morphology of Rubus prickle development and the molecular investigation of early prickle development genes. Department of Biology, The University Of Central Arkansas, Conway, BS (Hons) Thesis.

Kellogg, A.A., T.J. Branaman, N.M. Jones, C.Z. Little, and J.D. Swanson. 2011. Morphological studies of developing Rubus prickles suggest that they are modified glandular trichomes. Botany 89(4):217-226.

Mahmoud, S.S. and R.B. Croteau. 2002. Strategies for transgenic manipulation of monoterpene biosynthesis in plants. Trends Plant Sci. 7(8):366-373.

Marks, M.D., J.P. Wenger, E. Gilding, R. Jilk, and R.A. Dixon. 2009. Transcriptome analysis of Arabidopsis Wild-Type and gl3-sst sim trichomes identifies four additional genes required for trichome development. Mol. Plant 2(4):803-822.

Pandey, S., R. Goel, A. Bhardwaj, M.H. Asif, S.V. Sawant, and P. Misra. 2018. Transcriptome analysis provides insight into prickle development and its link to defense and secondary metabolism in Solanum viarum dunal. Sci. Rep. 8:17092.

Posluszny, U. and J.B. Fisher. 2000. Thorn and hook ontogeny in Artabotrys hexapetalus (Annonaceae). Amer. J. Bot. 87(11):15611570.

Rajapakse, S., L. Zhang, R. Ballard, and D. Byrne. 2001. AFLP marker development in rose for genetic mapping: Comparison of three restriction enzyme pairs. Acta Hort. 546:619-627.

Schilmiller, A.L., R.L. Last, and E. Pichersky. 2008. Harnessing plant trichome biochemistry for the production of useful compounds. Plant J. 54(4):702-711.

Schuepp, P.H. 1993. Tansley review No. 59. Leaf boundary layers. New Phytol. 125:477-507.

Szymanski, D.B., A.M. Lloyd, and M.D. Marks. 2000. Progress in the molecular genetic analysis of trichome initiation and morphogenesis in Arabidopsis. Trends Plant Sci. 5(5):214-219.

Wagner, G.J. 1991. Secreting glandular trichomes: More than just hairs. Plant Physiol. 96(3):675679.

Wagner, G., E. Wang, and R. Shepherd. 2004. New approaches for studying and exploiting an old protuberance, the plant trichome. Ann. Bot. 93(1):3-11. 